\title{
ФИНАНСИРОВАНИЕ ПРОИЗВОДСТВА ГРАЖДАНСКОЙ ПРОДУКЦИИ НА ПРЕДПРИЯТИЯХ ОПК: ТРАНСФОРМАЦИЯ БИЗНЕС-ПРОЦЕССОВ
}

\author{
(c) 2019 Бакулина Анна Александровна \\ доктор экономических наук, доцент, профессор Департамента корпоративных финансов \\ и корпоративного управления, заместитель проректора по научной работе \\ Финансовый университет при Правительстве Российской Федерации», Россия, Москва \\ E-mail: abakulina@fa.ru
}

\section{(c) 2019 Назырова Диана Рамильевна}

кандидат экономических наук, доцент кафедры налогов и налогообложения Уфимский государственный авиационный технический университет, Россия, Уфа

E-mail: nazyrova.diana@gmail.com

\section{(c) 2019 Топчий Павел Павлович}

аспирант Департамента Корпоративных финансов и корпоративного управления Финансовый университет при Правительстве Российской Федерации», Россия, Москва заместитель генерального директора по стратегическому развитию ООО «Центр оценки собственности «МОРФ», Россия, Москва

E-mail: paultop4i@yandex.ru

Предметом исследования является трансформация бизнес-процессов на предприятиях оборонно-промышленного комплекса (ОПК) как необходимое условие успешного развития отрасли.

Целью является исследование аспектов финансовой деятельности и финансирования производства гражданской продукции на предприятиях ОПК. Авторы исходили из того, что под влиянием внешней среды, в том числе усиления санкционного давления, предприятия ОПК вынуждены обращаться к заемным источникам финансирования, что, в конечном итоге, замедляет процессы диверсификации в отрасли.

Используя методы логического и сравнительного анализа, общенаучные методы исследования, авторами констатируется возможность применения метода DMAIC для ускорения трансформации бизнес-процессов, в том числе активизации внедрения цифровых технологий в производственный процесс, сокращения непроизводственных потерь.

Выводы. Ускорение трансформации бизнес-процессов при помощи подхода DMAIC будет способствовать сокращению сроков диверсификации, поскольку сократятся и сроки трансформации, что должно привести к сокращению сроков окупаемости инвестиционных вложений предприятий ОПК как первой, так и второй группы - для инновационных и реновационных проектов, соответственно.

Ключевые слова: Оборонно-промышленный комплекс, трансформация, бизнес-процессы, финансирование, структура источников финансирования, методы управления, DMAIC

Современное предприятие ОПК имеет разветвленную структуру бизнес-процессов, включающую разработку продуктов, тестирование и отладку, производство компонентов, сборку в готовое изделие, сопровождение и ремонт во время эксплуатации, а также утилизацию.

Следует отметить, что в условиях кооперации (большинство предприятий ОПК входят в состав шести крупнейших промышленных холдингов: Объединенную авиастроительную корпорацию (ОАК), Объединенную двигателестроительную корпорацию (ОДК), Объединенную судостроительную корпорацию (ОСК), Ростехнологии, Роскосмос и Росатом), достаточно сильно развитой в отрасли, на различных этапах жизненного цикла разработкой и производством изделий занимаются различные предприятия ОПК: разработкой - одни, отладкой и доводкой до промышленного применения - другие, массовым производством - третьи, эксплуатацией - четвертые, ремонтом и обслуживанием - пятые.

Проекты по диверсификации предприятия 
ОПК на производство гражданской продукции условно подразделяются на две группы: высокоэффективные исследовательские проекты, предполагающие инновации [1] (разработка и создание нового продукта, полностью меняющего бизнес-модель предприятия) и реновация существующего продукта (использование продукции, ранее поставляемой по ГОЗ, в гражданской отрасли, например, в топливно-энергетическом комплексе). У каждой группы будут отличаться приоритеты трансформации бизнес-процессов и источники финансирования.

При осуществлении инвестиций на диверсификацию производства в сферу гражданской продукции, помимо финансового состояния предприятия, должны учитываться: длительный срок производства продукции, значительные затраты ресурсов и времени на этапах разработки продуктов и вывода их на рынок [2].

Кроме того, при трансформации бизнеспроцессов необходимо учитывать: сложившуюся нормативную базу и номенклатуру стандартной для предприятия ОПК продукции, каталог знаний и компетенций, научно-производственную базу, базовые промышленные технологии в виде набора справочников, а также возможность внедрения цифровых технологий в производственные процессы.

Информационное агентство «Оружие России» на сайте публикует каталог ведущих предприятий-производителей отрасли с целью информационно-справочной поддержки основных направлений военно-технического сотрудничества и деятельности обороннопромышленного комплекса России [3].

Согласно этому списку, отобраны три предприятия, где, по мнению авторов статьи, возможна диверсификация в производство гражданской продукции; проанализированы финансовое состояние, структура источников финансирования деятельности в 2017-2018 гг. по данным официальной, опубликованной в открытом доступе, бухгалтерской (финансовой) отчетности [4].

1. Акционерное общество «Муромский радиозавод» (АО «Муромский радиозавод») - производитель аппаратуры громкоговорящей связи для ВМФ, коммерческого флота, морских нефтегазовых платформ.

2. Публичное акционерное общество «Арзамасский машиностроительный завод» (ПАО «Арзамасский машиностроительный завод») производитель военной техники, автозапчастей и спецтехники. Производит колёсные бронетранспортеры, специальную технику на их базе и лёгкие бронированные машины, в том числе на экспорт в Йемен, Китай, страны Африки и Ближнего Востока (сократился в связи с действием санкций).

3. Публичное акционерное общество «Агрегат» (ПАО «Агрегат») - производитель авиационно-технического назначения и промышленную гидравлику для легковых автомобилей и специальной техники.

Анализ финансовых результатов деятельности исследуемых предприятий (табл.1) показал, что в 2017-2018 гг. наблюдается снижение выручки от реализации продукции

Несмотря на этот факт, наиболее диверсифицированное предприятие - ПАО «Арзамасский машиностроительный завод» (выпускает запасные части к автомобилям «Газель») смогло добиться существенного увеличения показателей рентабельности за счет увеличения продаж на

Таблица 1. Динамика основных показателей результативности деятельности исследуемых предприятий ОПК в 2017-2018 гг.

\begin{tabular}{|c|c|c|c|c|c|c|}
\hline \multirow[t]{2}{*}{ Наименование показателя } & \multicolumn{2}{|c|}{$\begin{array}{c}\text { АО «Муромский } \\
\text { радиозавод» }\end{array}$} & \multicolumn{2}{|c|}{$\begin{array}{c}\text { ПАО «Арзамасский } \\
\text { машиностроитель- } \\
\text { ный завод» }\end{array}$} & \multicolumn{2}{|c|}{ ПАО «Агрегат» } \\
\hline & 2017 г. & 2018 г. & 2017 г. & 2018 г. & 2017 г. & 2018 г. \\
\hline Выручка от реализации, тыс.руб. & 577549 & 442585 & 15027817 & 13707213 & 3895871 & 3818236 \\
\hline Темп прироста,\% & & $-23,37$ & & $-8,79$ & & $-1,99$ \\
\hline Себестоимость реализации, тыс.руб. & 512845 & 388964 & 10778115 & 9403928 & 2652967 & 2514306 \\
\hline Темп прироста,\% & & $-24,16$ & & $-12,75$ & & $-5,23$ \\
\hline Чистая прибыль, тыс.руб. & 532 & 234 & 511389 & 1655686 & 428004 & 442618 \\
\hline Темп прироста,\% & & $-56,02$ & & 223,76 & & 3,41 \\
\hline Рентабельность продаж,\% & $11,05 \%$ & $11,89 \%$ & $6,67 \%$ & $16,16 \%$ & $16,54 \%$ & $17,33 \%$ \\
\hline Рентабельность собственного капитала, \% & $0,84 \%$ & $0,20 \%$ & $10,61 \%$ & $26,51 \%$ & $21,16 \%$ & $18,13 \%$ \\
\hline
\end{tabular}


внутреннем рынке.

Структура источников финансирования деятельности исследуемых предприятий представлена на рисунке 1 .

Установлено, что заемные источники (в том числе банковские кредиты) по удельному весу превышают собственные источники финансирования у АО «Муромский радиозавод» и ПАО «Арзамасский машиностроительный завод». Так, на начало 2019 года удельный вес заемных источников у АО «Муромский радиозавод» составлял
83,4\%, у ПАО «Арзамасский машиностроительный завод» составляет 50,9\%.

Перманентное использование банковских кредитов в качестве источника финансирования инициирует снижение финансовых результатов, поскольку в Российской Федерации высокие ставки по кредитам нефинансовым организациям по сравнению с европейскими.

По данным элементного состава кредитов, полученных исследуемых предприятиями в 2017-2018 гг. (рис.2) установлено, что на начало

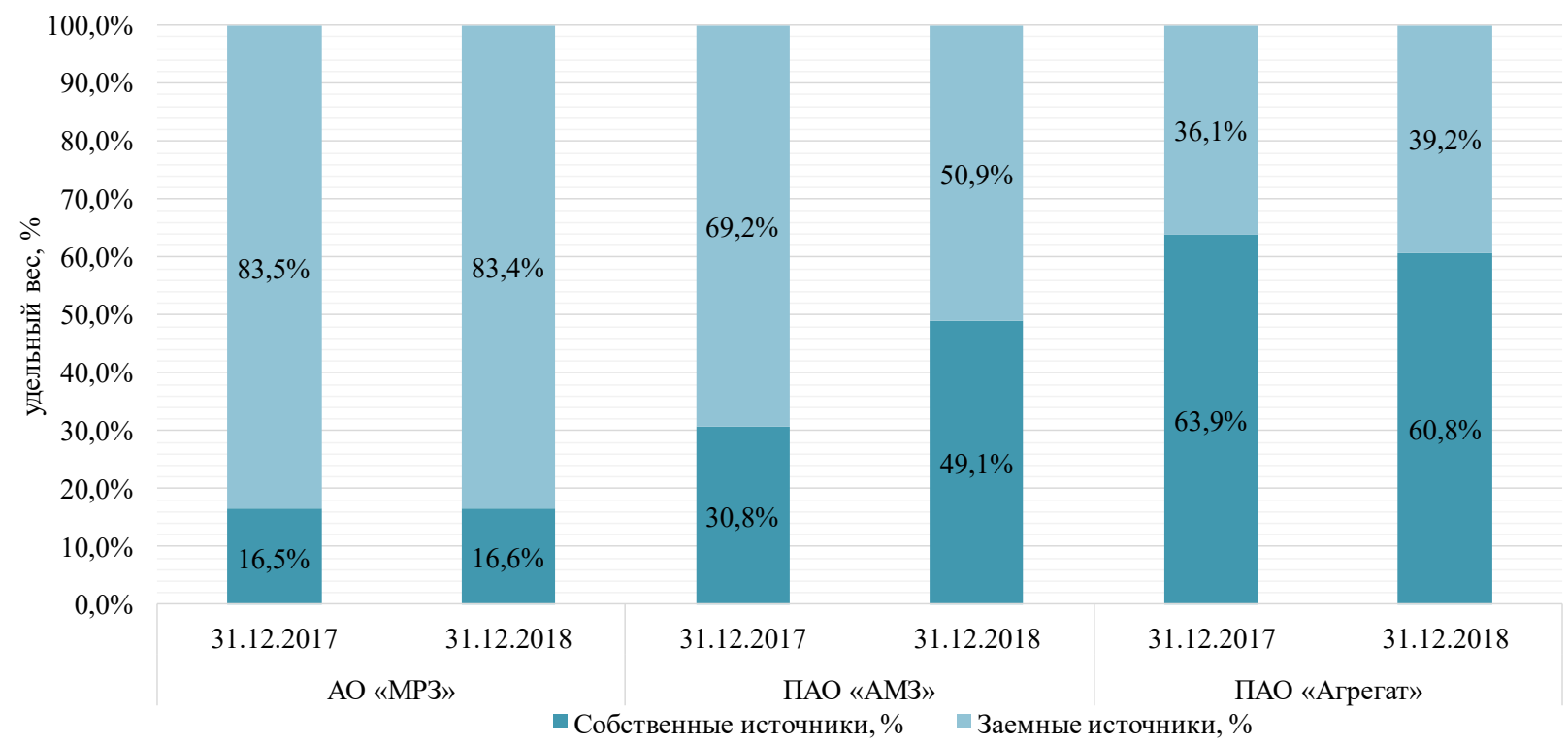

Puc. 1. Структура источников финансирования деятельности исследуемых предприятий ОПК в 2017-2018 гг.

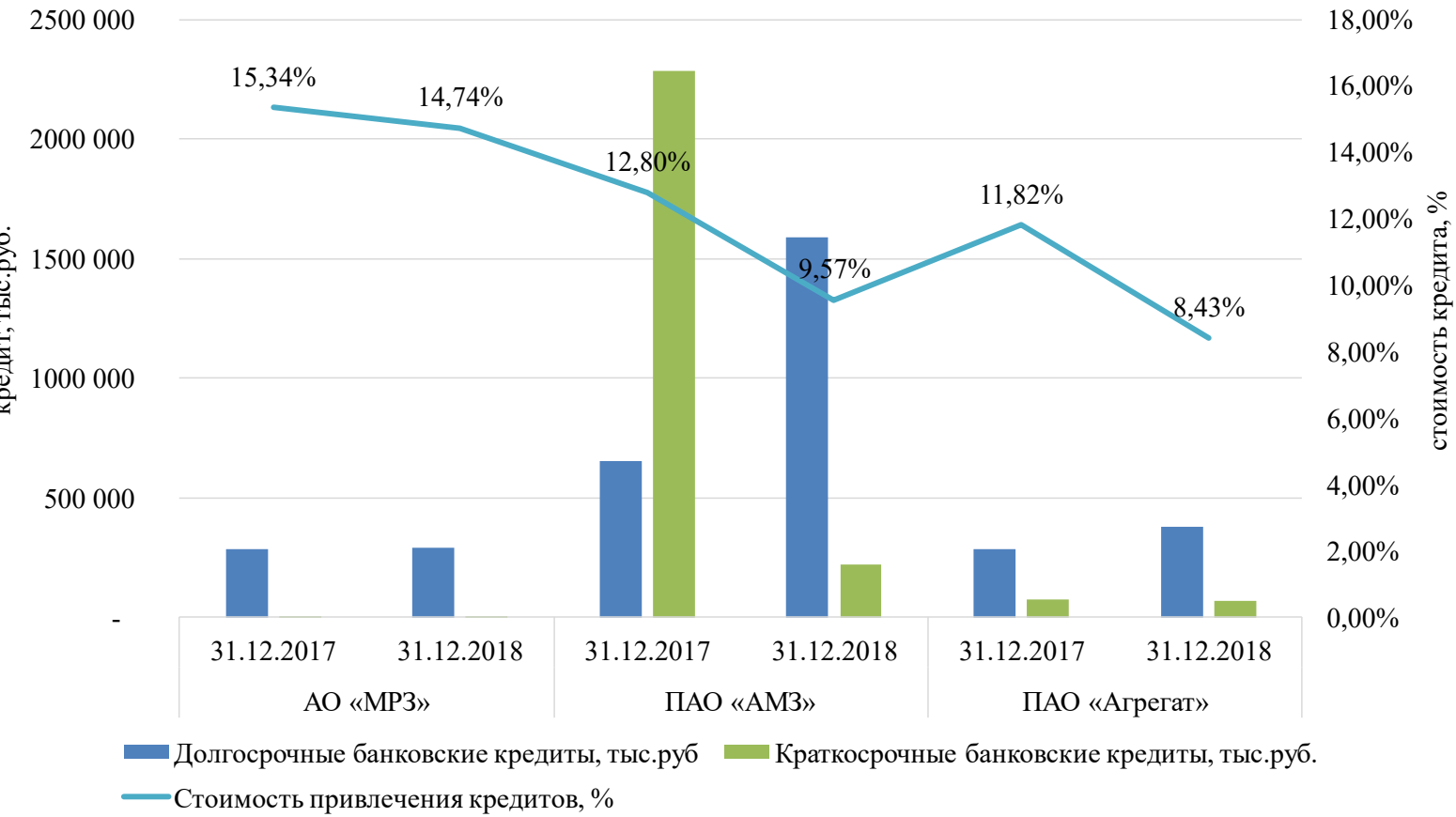

Puc. 2. Динамика банковских кредитов исследуемых предприятий ОПК и стоимости их привлечения в 2017-2018 гг. 
2019 года долгосрочные кредиты превалируют над краткосрочными.

Среднее значение стоимости привлечения банковского кредита в 2017-2018 гг. для исследуемых предприятий составило 12,12\%. Полученные кредиты направлялись на обновление основных производственных фондов (приобретение оборудования), ремонтные работы (ремонт производственных помещений). При этом существенного расширения деятельности в сторону наращивания объемов производства гражданской продукции у АО «Муромский радиозавод» и ПАО «Агрегат» за 2017-2018 гг. не наблюдалось.

АО «Муромский радиозавод» выпускает системы, которые устанавливаются на морских и речных судах, кораблях и подводных лодках без ограничения района плавания, на атомных и тепловых электростанциях, в метрополитенах, на металлургических, химических и других промышленных предприятиях, в ведомственных структурах и объектах специального назначения, там, где требуется надежная оперативная связь [5]. Несмотря на явную возможность к увеличению реализации продукции на гражданском рынке, особого прироста выручки у АО «Муромский радиозавод» не наблюдается. Следовательно, требуется реновация продукта (вторая группа) - поиск и освоение новых видов гражданской продукции.

Аналогично складывается и ситуация у второго анализируемого нами предприятия - ПАО «Арзамасский машиностроительный завод». Основными потребителями продукции предприятия были и остаются силовые ведомства Российской Федерации - Министерство обороны, Министерство внутренних дел, Федеральная служба безопасности, Федеральная служба охраны. Объем производства и возможность его на- ращивания ограничиваются наличием государственного оборонного заказа (ГОЗ).

Следовательно, снижение ГОЗ ведет к снижению доходов предприятия. Снижению заемных источников финансирования деятельности ПАО «Арзамасский машиностроительный завод», до введения санкций, в определенной степени способствовал факт роста объемов экспорта продукции [6].

При этом руководство ПАО «Арзамасский машиностроительный завод» предполагает, что экспортная направленность поможет предприятию в работе по диверсификации производства, поскольку связи с зарубежными партнерами позволят более эффективно выстраивать цепочки сбыта новой продукции, которая будет выпускаться по программе конверсии [6]. Но в условиях ухудшения внешнеполитических условий существенного увеличения чистой прибыли, как основы собственных источников финансирования, в 2018 году не наблюдается.

Третье предприятие - ПАО «Агрегат» - более 75-ти лет является неотъемлемой частью российского аэрокосмического комплекса и одним из лидеров авиационного агрегатостроения. Основную долю производства составляет продукция авиационно-технического назначения: агрегаты гидравлических и пневматических систем, использующихся в составе большинства выпускаемых в России летательных аппаратов, а также сложная топливно-регулирующая аппаратура. С 1995 года ПАО «Агрегат» серийно выпускает гидравлический аварийно-спасательный инструмент, применяемый в структурах МЧС, МВД, ЖКХ и других сферах жизнеобеспечения. Предприятие также производит промышленную гидравлику для легковых автомобилей и специальной техники [7]. Наращивание именно этой составляющей бизнеса и является осно-

Таблица 2. Динамика показателей ликвидности исследуемых предприятий ОПК в 2017-2018 гг.

\begin{tabular}{|l|c|c|c|c|c|c|}
\hline \multicolumn{1}{|c|}{ Наименование показателя } & \multicolumn{2}{|c|}{$\begin{array}{c}\text { АО «Муромский } \\
\text { радиозавод» }\end{array}$} & \multicolumn{1}{|c|}{$\begin{array}{c}\text { ПАО «Арзамасский } \\
\text { машиностроитель- } \\
\text { ный завод» }\end{array}$} & \multicolumn{2}{|c|}{ ПАО «Агрегат» } \\
\cline { 2 - 7 } & 2017 г. & 2018 г. & 2017 г. & 2018 г. & 2017 г. & 2018 г. \\
\hline $\begin{array}{l}\text { Коэффициент абсолютной ликви- } \\
\text { дности, отн.ед }\end{array}$ & 0,01 & 0,01 & 0,09 & 0,09 & 0,20 & 0,34 \\
\hline $\begin{array}{l}\text { Коэффициент «критической точки» } \\
\text { (коэффициент быстрой ликвидности } \\
\text { или срочной ликвидности), отн.ед }\end{array}$ & 0,61 & 0,45 & 0,80 & 0,83 & 0,75 & 0,84 \\
\hline $\begin{array}{l}\text { Коэффициент текущей ликвидности } \\
\text { (коэффициент покрытия), отн.ед }\end{array}$ & 1,45 & 1,53 & 1,32 & 1,43 & 1,31 & 1,29 \\
\hline $\begin{array}{l}\text { Доля оборотных средств в активах, } \\
\text { отн.ед. }\end{array}$ & 0,70 & 0,64 & 0,70 & 0,66 & 0,35 & 0,36 \\
\hline
\end{tabular}


вой диверсификации ПАО «Агрегат». Основным драйвером развития ПАО «Агрегат» в 2018 году и причиной увеличения собственного капитала (значение собственные оборотные средства стали положительны) стала активизация работы с топливно-энергетическим комплексом [11].

Следует констатировать тот факт, что в текущих условиях российской экономики без привлечения заемного финансирования диверсификация ОПК на производство гражданской продукции невозможна для инновационных проектов (первая группа в вышепредставленной нами градации). Этот факт подтверждают и низкие показатели ликвидности (таблица 2) и финансовой устойчивости (таблица 3).

В целях ускорения трансформации бизнеспроцессов в отрасли в сторону диверсификации деятельности в производство гражданской продукции рекомендуется воспользоваться современные технологиями управления.

На сегодняшний день технологии управления, способствующие эффективной организации бизнес-процессов включают теорию ограничений, управление проектами, Agile-подход (гибкие методологии управления) и МВО («управление по целям»).

Так, Agile-подход успешно внедрен в ООО «Газпромнефть НТЦ». Компания пользуется методологией Agile в следующем порядке: сбор идей (ориентировочно 300 проектов), защита каждого проекта перед руководством (должно остаться примерно 100 проектов), реализация прототипа (около 25 проектов), пилотное внедрение прототипов. Десять проектов, прошедших такой отбор, передаются в промышленную эксплуатацию. На каждый сплит отбора компания затрачивает около полугода [8].

В современной методологии происходит слияние двух подходов - японского Lean и американского Six Sigma - концепция Lean 6 Sigma

Данная концепция представляет собой систему инструментов, которая сфокусирована на непрерывном качественном улучшении внутренних процессов с одновременным повышением удовлетворенности клиентов и сотрудников.

По концепции 6 Sigma продукт или услуга оценивается не изнутри, а снаружи, т.е. «глазами клиента». Сама по себе методология имеет сложный математический инструментарий, одним из ее ключевых подходов является DMAIC поэтапная оптимизация процессов (рис. 3).

По мнению бизнес-экспертов, метод DMAIC позволяет сократить длительность бизнеспроцессов, найти «проблемные места» в организации труда и устранить потери [9]. Следовательно, его возможно применить для трансформации бизнес-процессов предприятий ОПК.

Таблица 3. Динамика показателей финансовой устойчивости исследуемых предприятий ОПК в 20172018 гг.

\begin{tabular}{|l|c|c|c|c|c|c|}
\hline \multirow{2}{*}{ Наименование показателя } & \multicolumn{2}{|c|}{$\begin{array}{c}\text { AО «Муромский радио- } \\
\text { завод» }\end{array}$} & \multicolumn{2}{|c|}{$\begin{array}{c}\text { ПАО «Арзамасский } \\
\text { машиностроительный }\end{array}$} & \multicolumn{2}{|c|}{ ПАО «Агрегат» } \\
\cline { 2 - 7 } & 2017 г. & 2018 г. & 2017 г. & 2018 г. & 2017 г. & 2018 г. \\
\hline $\begin{array}{l}\text { Коэффициент капитали- } \\
\text { зации (плечо финансового } \\
\text { рычага), отн.ед. }\end{array}$ & 9,58 & 5,04 & 2,74 & 1,53 & 0,62 & 0,61 \\
\hline $\begin{array}{l}\text { Собственные оборотные } \\
\text { средства, тыс.руб. }\end{array}$ & -155244 & -137788 & $-642529,50$ & 793552,00 & $-109043,00$ & $-60768,00$ \\
\hline $\begin{array}{l}\text { Коэффициент обеспеченно- } \\
\text { сти запасов собственными } \\
\text { источниками, отн.ед. }\end{array}$ & $-0,54$ & $-0,45$ & $-0,17$ & 0,28 & $-0,22$ & $-0,12$ \\
\hline $\begin{array}{l}\text { Коэффициент автономии } \\
\text { (концентрации собственного } \\
\text { капитала), отн.ед. }\end{array}$ & 0,09 & 0,17 & 0,27 & 0,40 & 0,62 & 0,62 \\
\hline $\begin{array}{l}\text { Коэффициент финансирова- } \\
\text { ния, отн.ед. }\end{array}$ & 0,10 & 0,20 & 0,37 & 0,65 & 1,61 & 1,64 \\
\hline $\begin{array}{l}\text { Коэффициент финансовой } \\
\text { устойчивости, отн.ед. }\end{array}$ & 0,45 & 0,58 & 0,47 & 0,54 & 0,73 & 0,72 \\
\hline $\begin{array}{l}\text { Коэффициент маневренно- } \\
\text { сти, отн.ед. }\end{array}$ & $-2,45$ & $-1,20$ & $-0,13$ & 0,13 & $-0,05$ & $-0,02$ \\
\hline $\begin{array}{l}\text { Коэффициент иммобилиза- } \\
\text { ции, отн.ед. }\end{array}$ & 0,43 & 0,57 & 0,44 & 0,53 & 1,86 & 1,76 \\
\hline
\end{tabular}




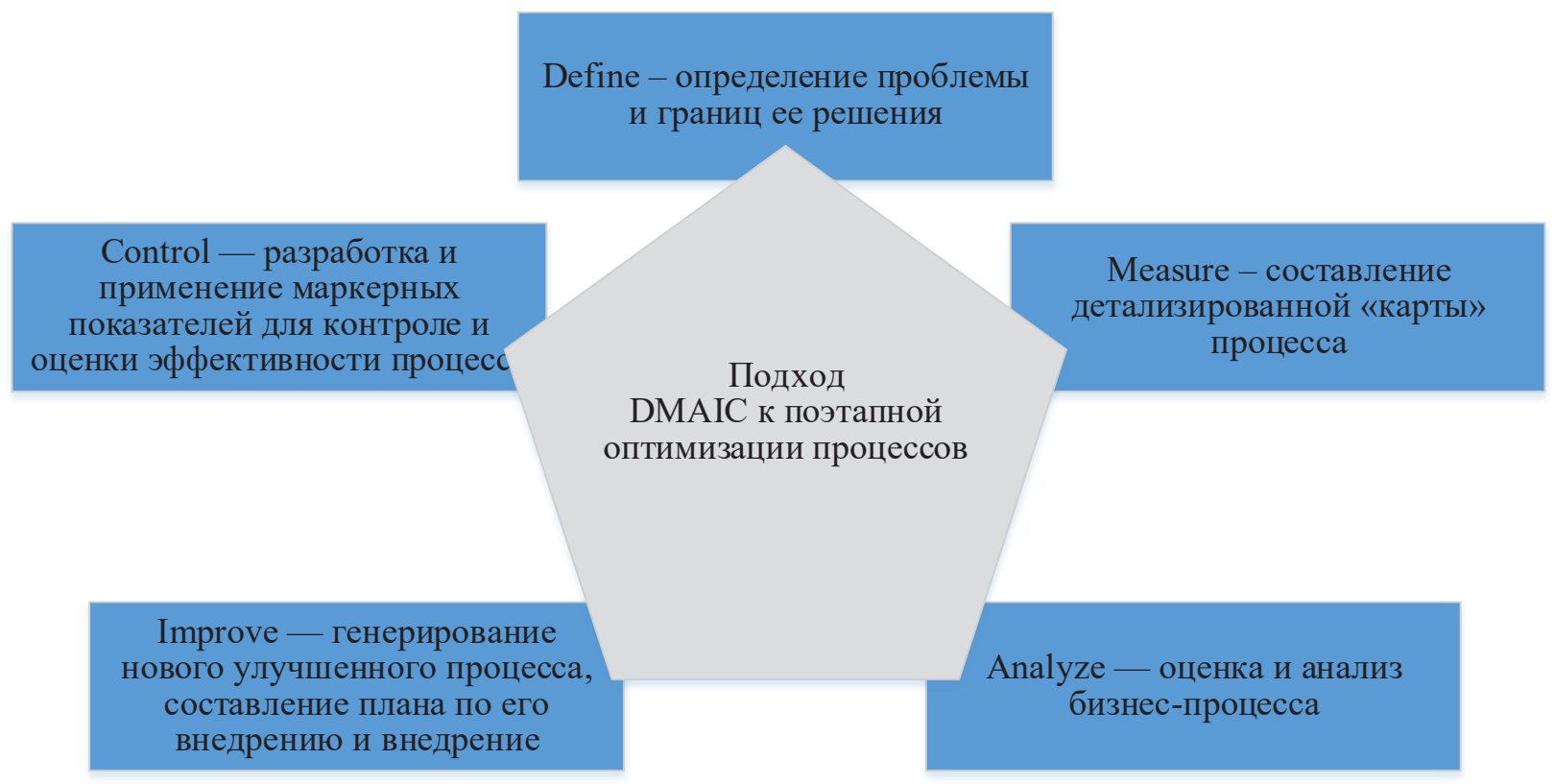

Puc. 3. Подход DMAIC к поэтапной оптимизации процессов.

Отметим, что в зарубежных исследованиях уже существует расширенная версия подхода - eDMAIC - позволяющая включить элементы цифровых технологий в производственные процессы, и спрогнозировать эффект от такого внедрения [10]. Расширенная версия предполагает стандартизацию управления процессами обработки в производстве, а также учитывает большее количество вариативных факторов, способных изменить ситуацию в производ- ственных процессах.

Ускорение трансформации бизнес-процессов при помощи подхода DMAIC будет способствовать сокращению сроков диверсификации, поскольку сократятся и сроки трансформации, что в конечном итоге должно привести к сокращению сроков окупаемости инвестиционных вложений предприятий ОПК как первой, так и второй группы - для инновационных и реновационных проектов соответственно.

\section{Библиографический список}

1. Бакулина А.А. Развитие инновационного потенциала региона силами оборонной промышленности / Бакулина Анна Александровна, Топчий Павел Павлович, Солонинкина Анастасия Максимовна // Управленческие науки. 2017. № 4. URL: https://cyberleninka.ru/article/n/razvitie-innovatsionnogo-potentsiala-regionasilami-oboronnoy-promyshlennosti (дата обращения: 20.04.2019).

2. Бакулина А.А. Проблемы совершенствования учета накладных расходов предприятий обороннопромышленного комплекса / Бакулина Анна Александровна, Алексеев Александр Александрович, Топчий Павел Павлович // Учет. Анализ. Аудит. 2017. № 5. URL: https://cyberleninka.ru/article/n/problemysovershenstvovaniya-ucheta-nakladnyh-rashodov-predpriyatiy-oboronno-promyshlennogo-kompleksa (дата обращения: 20.04.2019).

3. Официальный сайт Информационного агентства «Оружие России» (Свидетельство о регистрации средства массовой информации Эл № ФС77-61922). Каталог ведущих предприятий-производителей отрасли (http://www.arms-expo.ru/armament/members/589/)

4. Сервер раскрытия информации. Бухгалтерская отчетность предприятий. http://www.e-disclosure.ru $\mathrm{AO}$ «Муромский радиозавод». http://www.e-disclosure.ru/portal/files.aspx?id=8529\&type=3

ПАО «Арзамасский машиностроительный завод» http://www.e-disclosure.ru/portal/files.aspx?id=4258\&type=3 ПАО «Агрегат» http://www.e-disclosure.ru/portal/files.aspx?id=9992 \&type=3

5. Официальный сайт АО «Муромский радиозавод». http://muromrz.com/

6. Официальный сайт ПАО «Арзамасский машиностроительный завод» http:/www.amz.ru/

7. Официальный сайт ПАО «Агрегат». http://www.agregat-avia.ru/ 
8. Опытные трансформаторы. На конференции «Цифровой бизнес-2019» ИТ-директоры обменялись опытом цифровой трансформации. http://www.connect-wit.ru/opytnye-transformatory-na-konferentsii-tsifrovojbiznes-2019-it-direktory-obmenyalis-opytom-tsifrovoj-transformatsii.html

9. Lean-перезагрузка, или Как повысить эффективность бизнеса? https://realnoevremya.ru/articles/136208kak-podnyat-effektivnost-biznes-processov-i-snizit-rashody

10. An Enhanced DMAIC Method for Feature-Driven Continuous Quality Improvement for Multi-Stage Machining Processes in One-of-a-Kind and Small-Batch Production. 11.01.2019. https://ieeexplore.ieee.org/stamp/stamp. jsp?arnumber $=8648418$

11. Гидравлика для нефтепроводов http://www.agregat-avia.ru/produktsija/promyshlennaja-gidravlika 